\begin{abstract}
Iranica
Abstracta Iranica Revue bibliographique pour le domaine irano-aryen

Volume 42-43 | 2021

Comptes rendus des publications de 2019-2020
\end{abstract}

\title{
Daniel King (ed.). The Syriac World
}

\section{Christelle Jullien}

\section{(2) OpenEdition \\ Journals}

Édition électronique

URL : https://journals.openedition.org/abstractairanica/51652

DOI : 10.4000/abstractairanica.51652

ISSN : 1961-960X

Éditeur :

CNRS (UMR 7528 Mondes iraniens et indiens), Éditions de l'IFRI

\section{Référence électronique}

Christelle Jullien, « Daniel King (ed.). The Syriac World», Abstracta Iranica [En ligne], Volume 42-43 | 2021, document 1, mis en ligne le 30 décembre 2020, consulté le 16 décembre 2022. URL : http:// journals.openedition.org/abstractairanica/51652; DOI : https://doi.org/10.4000/abstractairanica. 51652

Ce document a été généré automatiquement le 16 décembre 2022.

Tous droits réservés 


\title{
Daniel King (ed.). The Syriac World
}

\author{
Christelle Jullien
}

\section{RÉFÉRENCE}

Daniel King (ed.). The Syriac World, London: Routledge, 2019, p. lii + 842. ISBN

9780367732363

$1 \quad$ Nouveau manuel de référence de la série Routledge Worlds, des Éditions Routledge, cet ouvrage de type encyclopédique est consacré au monde syriaque, sa langue, son histoire, sa littérature, ses expressions religieuses, etc. Il comprend une vingtaine de contributeurs internationaux, sous la direction de Daniel King, de l'Université de Cardiff en Angleterre, coordinateur et éditeur général du volume. Celui-ci s'adresse à une large audience : public universitaire, averti ou curieux, mais aussi spécialistes du domaine.

2 L'organisation de l'ouvrage est pluripartite. La première section ("Backgrounds", p. 11-43) resitue l'histoire des communautés syriaques et de leurs productions dans l'Antiquité tardive à travers le prisme d'un double contexte historique et sociopolitique : celui de l'empire romain oriental (chap. 1, M. Debié) et celui de l'empire sassanide (chap. 2, T. Daryaee). Chaque chapitre, sur une chronologie développée, traite $\mathrm{du}$ développement et de l'organisation de ces communautés, de leur relation au pouvoir, du façonnement de leur identité.

3 La seconde section ("The Syriac World in Late Antiquity", p. 47-201) approfondit des thématiques abordées en zoom. Plusieurs chapitres ont trait par exemple aux relations inter-religieuses entre chrétiens et religions traditionnelles dites "païennes" (chap. 3, J. Healey), entre chrétiens syriaques et juifs, spécialement sur la question des influences récipoques (chap. 9, M. Bar-Asher Siegal), et avec les musulmans avec un survol des récits d'écrivains syriaques sur la conquête arabe et l'arrivée de l'islam (chap.11, M. Penn). D'autres abordent la question des origines : récits d'origine de la christianisation de la Mésopotamie (chap. 4, D. Taylor qui évoque une rivalité de traditions entre Édesse et Nisibe); formation des Églises syriaques dans leur diversité au moment des 
controverses christologiques sur la double nature du Christ, Dieu et homme, et des conciles (chap. 6, V. Menze ; chap. 12, D. Wilmshurst), ainsi que les dénominations des Églises (chap. 7, D. Winkler). Un chapitre est dévolu aux formes de la vie religieuse et aux pratiques du monachisme syriaque : membre de l'ordre, ermites, divers aspects de l'ascétisme, semi-cénobites, cénobites (chap. 5, F. Jullien). Deux chapitres rejoignent la thématique de la première partie et auraient sans doute gagné à s'y insérer : ils traitent des formes de l'adaptation des chrétiens dans les contextes romain et perse : histoire des Syro-occidentaux et formation de leur identité en milieu romain (chap. 10, $\mathrm{N}$. Andrade) ; histoire de l'Église d'Orient sous les Sassanides puis sous le califat abbasside (chap. 8, G. Herman).

4 La troisième partie (“The Syriac Language”, p. 205-289) est consacrée à la langue syriaque : émergence du syriaque et ses rapports avec les langues araméennes (chap. 13, H. Gzella), évolution de la langue à travers ses expressions littéraires depuis ses formes primitives jusqu'au syriaque classique et post-classique (chap. 14, A. M. Butts). Y sont aussi traités les supports matériels de l'écrit et de sa transmission (inscriptions et manuscrits), l'histoire des systèmes d'écriture (chap.15, F. Briquel-Chatonnet), ainsi qu'une présentation des dialectes néo-araméens encore parlés par les communautés chrétiennes et juives de certaines régions de Syrie, Turquie, Irak et Iran (chap. 16, G. Khan).

5 La quatrième partie ("Syriac Literary, Artistic, and Material Culture in Late Antiquity", p. 293-580) traite de la littérature syriaque et de la culture matérielle. Dans une perspective chronologique, les premiers chapitres sont consacrés au domaine biblique (traductions en syriaque, traditions d'interprétations dans les textes syro-orientaux et occidentaux, chap. 17, J. Loopstra) et à la littérature ancienne (Odes de Salomon, Actes de Thomas, Livre des lois des pays, attribué à Bardesane, œuvres d'Éphrem et d'Aphraate (chap. 18, U. Possekel. Les suivants ont chacun pour objet un genre littéraire différent : écrits poétiques (chap.19, S. Brock), hagiographie (chap. 20, J.-N. Mellon Saint-Laurent), mystique (chap. 21, A. Pirtea), théologie et débats (chap. 22, Th. Hainthaler), historiographie (chap. 24, Ph. Wood), philosophie et son héritage grec (chap. 25, J. W. Watt), médical (chap. 26, G Kessel). Le chapitre 22 rejoint d'ailleurs les lignes thématiques des chapitres 6,7 et 12 et aurait pu s'insérer dans la deuxièle partie. Plusieurs contributions ont trait à la vie des Églises : liturgie et leurs différents rites dans les Églises syriaques (chap. 23, B. Varghese), mais aussi culture matérielle présentée à travers les peintures murales (chap. 27, E. Loosley) et l'architecture des lieux de culte (chap. 28, W. Khoury). D'autres ont trait à la vie pratique : agriculture (chap. 30, M. J. Decker) et rôle des femmes et des enfants (chap. 29, S. Ashbrook Harvey).

6 La dernière et cinquième partie ("Syriac Christianity Beyond the Ancient World", p. 583-796) concerne les développements des Églises dans des milieux géographiques et culturels différents durant l'Antiquité tardive et le haut Moyen Âge : en Asie centrale (chap. 31, M. Dickens), en Chine (chap. 32, H. Takahashi), en Inde (chap. 33, I. Perczel). D'autres chapitres font une synthèse de ces mouvements au Moyen-Orient à époque plus tardive : sous les Mongols puis les Ottomas (chap. 35, Th. Carlson), dans la tradition maronite (chap. 36, S. Abouzayd), en Europe (chap. 37, R. J. Wilkinson). D'un point de vue à la fois chronologique et diachronique, quelques chapitres abordent des thèmes comme la Renaissance syriaque des XII ${ }^{e}-\mathrm{XIII}^{\mathrm{e}}$ siècles (chap. 34, D. Weltecke, H. Younansardaroud), l'identité syriaque (chap. 38, H. Murre-van den Berg), les 
bouleversements politiques récents en Irak et leur impact sur les communautés chrétiennes syriaques depuis 1991 (chap. 39, E. Hunter), les premiers centres d'étude du syriaque en Europe (chap. 37, R. J. Wilkinson).

7 Trois appendices complètent le volume: une liste des patriarches des Églises syroorientale et syro-occidentale ; un index des sujets ; une bibliographie et des indications sur les ressources disponibles online sur les études syriaques. Un ensemble de cartes avec un index (p. 824-834 - D. Michelson, I. Mladjov) et des illustrations de qualité complètent le tout. Précisons que ces cartes sont libres de droits.

On notera que des sujets comme les sciences en syriaque, les questions calendaires, l'astrologie, les influences linguistiques étrangères ne sont pas abordées. Certaines entrées sont un peu redondantes (signalé supra) ; l'organisation du livre aurait sans doute mérité des regroupements. Un manque d'homogénéisation des graphies des toponymes et des noms propres nuit à la fluidité de lecture. Par exemple : Jundishapur (p. 191), Gondēshāpūr (p. 449), Gundeshapur (p. 570). Quelques petites erreurs à rectifier: Beth 'Ebe (p. 197) pour Beth 'Abe. En dépit de ces menues remarques, cet ouvrage est désormais référent: à la fois introduction à chacun des thèmes abordés, mais aussi petit précis utile aux spécialistes, il contribue hautement à la valorisation des études syriaques.

\section{AUTEURS}

CHRISTELLE JULLIEN

CNRS, CERMI, Paris 